\title{
Technical note: Effects of an epinephrine infusion on eye temperature and heart rate variability in bull calves
}

\author{
M. Stewart, ${ }^{* 1}$ J. R. Webster, ${ }^{*}$ K. J. Stafford,† A. L. Schaefer,‡ and G. A. Verkerk§ \\ ${ }^{*}$ AgResearch Ltd., Private Bag 3123, Hamilton 3240, New Zealand \\ †Massey University, Private Bag 11222, Palmerston North 4442, New Zealand \\ $\ddagger$ Agri-Food Canada, Lacombe Research Centre, 6000 C \& E Trail, Lacombe, Alberta, Canada T4L 1W1 \\ $\S D a i r y N Z$, Private Bag 3221, Hamilton 3240, New Zealand
}

\begin{abstract}
Changes in autonomic nervous system (ANS) activity are one of the first phases of a stress response, but they are rarely used to assess the welfare of farm animals. Eye temperature measured using infrared thermography (IRT) is proposed as an indicator of ANS activity because it may reflect changes in blood flow in the capillary beds of the conjunctiva. The aim was to determine whether epinephrine infusion would initiate eye temperature changes in calves. Sixteen 4-mo-old Friesian calves $(124 \pm 5 \mathrm{~kg})$ were assigned randomly to receive a jugular infusion of either epinephrine (4 $\mu \mathrm{g} / \mathrm{kg}$ per min for $5 \mathrm{~min}$ ) or saline. Eye temperature $\left({ }^{\circ} \mathrm{C}\right)$, heart rate $(\mathrm{HR})$, and $\mathrm{HR}$ variability (HRV) were recorded from 15 min before infusion until 10 min after it was completed. Blood samples collected via jugular catheter were assayed for epinephrine, norepinephrine, and cortisol concentrations, and packed cell volume (PCV) was measured. No changes in any variable were observed with the saline infusion. Plasma epinephrine concentrations increased 90-fold with epinephrine infusion, which was associated with a decrease in eye temperature of $1.4 \pm 0.05^{\circ} \mathrm{C}$. During epinephrine infusion, plasma norepinephrine concentrations decreased by half and HR decreased by $9.3 \pm 3.3$ beats/min. The HRV measure, the root mean square of successive differences, increased by $49.7 \pm 9.2 \mathrm{~ms}$, indicating a compensatory increase in parasympathetic activity. After epinephrine infusion, plasma cortisol concentrations increased by $10.4 \pm 1.7 \mathrm{ng} / \mathrm{mL}$ and PCV was higher (38 vs. $31 \pm$ $0.1 \%$, epinephrine vs. saline, respectively). These results support the hypothesis that changes in eye temperature are mediated by the sympathetic component of the ANS. Infrared thermography is a noninvasive method to assess ANS activity for evaluating welfare of cattle.
\end{abstract}

Key words: epinephrine, eye temperature, heart rate variability, infrared thermography

Received May 17, 2010.

Accepted July 7, 2010.

${ }^{1}$ Corresponding author: mairi.stewart@agresearch.co.nz
Measurements of autonomic nervous system (ANS) activity can provide useful information for farm animal welfare assessment. Catecholamines (e.g., epinephrine and norepinephrine) mediate the rapid adjustment of the "fight or flight" response so they provide more information about hyperacute pain and fear responses than the slower responding hypothalamic-pituitary-adrenal (HPA) axis. Increased epinephrine concentrations were found following branding (Lay et al., 1992a,b), isolation (Lefcourt and Elsasser, 1995), simulated transport (Locatelli et al., 1989), and dehorning (Mellor et al., 2002) in cattle. Plasma catecholamine concentrations are difficult to measure practically because physiological responses involve rapid change and plasma half-life is only 1 to 2 min (Hjemdahl, 1993). Furthermore, the handling required to sample blood may itself initiate catecholamine release, which can confound results. Autonomic activity has been measured in farm animals using changes consequential to catecholamine release including heart rate (HR) and HR variability (HRV), eye pupil diameter, skin resistance, peripheral blood flow, and packed cell volume (PCV).

Infrared thermography (IRT) measures radiated electromagnetic energy and has many applications in human and veterinary medicine (Yang and Yang, 1992) and animal welfare research (Stewart et al., 2005). Changes in eye temperature measured using IRT were used to assess stress and pain in cattle (Stewart et al., 2008b) and the authors proposed that changes in eye temperature were due to altered blood flow in capillary beds via sympathetically mediated vasoconstriction. Eye temperatures decreased in calves disbudded without local anesthetic, whereas calves given local anesthesia before disbudding had no change during the procedure. However, eye temperature decreased during recovery due to the onset of pain when the local anesthetic waned (Stewart et al., 2008b, 2009). Exposure to a fright or an electric prod resulted in decreased eye temperature (Stewart et al., 2008a). That eye temperature changes reflect ANS activity is supported by observations of synchronized changes in HRV that suggest an increase in sympathetic nervous system (SNS) tone 
and a reduction in parasympathetic nervous system (PNS) activity. Interpretation of HRV as a measure of SNS activity remains subject to debate; however, it is generally agreed that the root mean square of successive differences (RMSSD) is the primary time domain trait of HRV that indicates increased vagal regulatory tone (von Borell et al., 2007). To understand the role of the ANS in regulating eye temperature, the underlying physiological mechanisms need further investigation.

Stewart et al. (2007) reported that exogenous stimulation of the HPA axis by bolus administration of $\mathrm{ACTH}$ and bovine corticotrophin-releasing hormone did not affect eye temperature in dairy cows despite significant increases in circulating ACTH and cortisol. In the same study, a bolus injection of epinephrine $(1.4 \mu \mathrm{g} / \mathrm{kg}$ of BW) had no effect on eye temperature. This dose rate had metabolic effects with release of NEFA into the circulation (Kolver et al., 2001), but bolus administration may not have simulated the increases in plasma epinephrine concentrations experienced during acute stress and pain. Under natural conditions, the "fight or flight" response would occur over several minutes; therefore, infusion may more closely simulate endogenous epinephrine release after exposure to a noxious stimulus. In the present study, epinephrine was infused to simulate an increase in SNS activity and test the hypothesis that this would result in a decrease in eye temperature in cattle.

Sixteen 4-mo-old Friesian bull calves (124 $\pm 5 \mathrm{~kg})$ were managed outdoors on pasture under normal farm practice and accustomed to intensive handling in the facilities where the procedures would take place for 3 wk before the trial. During this time, calves were habituated to restraint in a calf chute (with a head catch, Cattlemaster, Te Pari Products, Oamaru, New Zealand) and to wearing HR monitors. On the day before treatment, bilateral indwelling jugular catheters were inserted, one for infusion and one for blood sampling. Calves were assigned randomly $(\mathrm{n}=8$ per treatment) to receive either epinephrine $\mathrm{HCl}(4 \mu \mathrm{g} /$ kg per min; Cat. no. E4642, Sigma Aldrich, St Louis, $\mathrm{MO}$ ) dissolved in approximately $60 \mathrm{~mL}$ of physiological saline (Baxter Healthcare, New South Wales, Australia) or an equivalent volume of physiological saline. Infusions were delivered using a Baxter Flo-Gard 6201 volumetric infusion pump (Baxter Healthcare, Deerfield, IL). Calves were allowed $1 \mathrm{~h}$ in a holding pen before sampling started. Approximately 15 min before sampling, each calf was fitted with a HR monitor and moved into the calf chute where it was restrained for infusion and sampling. Baseline data were collected for $15 \mathrm{~min}$ followed by the infusion (average time, 05:02 \pm 00:04 min:s), after which posttreatment responses were monitored for a further $10 \mathrm{~min}$.
An infrared thermography camera (ThermaCam S60, FLIR Systems AB, Danderyd, Sweden) was used to collect images of the eye from the left side of the calf (approximate distance $0.5 \mathrm{~m}$ ) at a $90^{\circ}$ angle from the direction the calf was facing. Maximum temperature $\left({ }^{\circ} \mathrm{C}\right)$ of the medial, posterior palpebral border of the lower eyelid and the lacrimal caruncle was recorded manually, approximately every $20 \mathrm{~s}$ over the sampling period. Ambient temperature $\left({ }^{\circ} \mathrm{C}\right)$ and relative humidity $(\%)$ in the work area were recorded every $30 \mathrm{~min}$ and entered into the infrared camera to calibrate it for atmospheric conditions.

Continuous inter-heartbeat intervals (IBI) were recorded using Polar HR monitors (S810i, Polar Electro Oy, Helsinki, Finland). Monitors were strapped firmly around the thorax immediately behind the forelimbs, with electrode contact points on areas from which hair had been removed and ultrasound transmission gel applied. The HR and IBI data were extracted using Polar Precision Performance Software (Version 4.03). Heart rate (recorded every second) was averaged over 1-min intervals, and IBI data were used to calculate the RMSSD using HRV software (Niskanen et al., 2004). To fulfill recommendations for analysis of HRV using fast Fourier transformation (Task Force of the European Society of Cardiology, North American Society of Pacing and Electrophysiology, 1996; von Borell et al., 2007), short segments of data containing 512 beats (512 IBI, approximately $5 \mathrm{~min}$ ) were examined.

Acute changes in epinephrine and norepinephrine concentrations were detected as continuous blood samples $(6 \mathrm{~mL})$ were collected using a peristaltic pump during successive 30-s intervals into prechilled EDTA tubes (Becton Dickinson, Plymouth, UK) from -2 until $10 \mathrm{~min}$ relative to the start of the infusion (time 0 ). Additional blood samples $(7 \mathrm{~mL})$ were taken for cortisol analysis at $-10,-5$, and $15 \mathrm{~min}$ into tubes containing lithium heparin (Becton Dickinson). Blood samples were immediately placed on ice and centrifuged $(1,300 \times g)$ at $4^{\circ} \mathrm{C}$ for $10 \mathrm{~min}$, within $10 \mathrm{~min}$ of collection. Plasma was stored at $-80^{\circ} \mathrm{C}$ until assayed. Selected samples were assayed for concentrations of epinephrine and norepinephrine at $-2,0,1,2,3,4,5,6,8$, and 10 min. Packed cell volume was measured in samples taken at -5 and 5 min. Cortisol was measured by double-antibody RIA (Fisher et al., 2002). The minimum detectable level was $1.0 \mathrm{ng} / \mathrm{mL}$. Interassay coefficients of variation for plasma pools measuring $8.3,24.4$, and $63.4 \mathrm{ng} / \mathrm{mL}$ were $1.8,10.0$, and 5.8\%, respectively. Epinephrine and norepinephrine were assayed when $20 \mu \mathrm{L}$ of $600 \mathrm{nmol} / \mathrm{L}$ $\mathrm{N}$-methyl dopamine internal standard was added to 1 $\mathrm{mL}$ of plasma and extracted on alumina. This extract was washed with sodium bicarbonate solution and water and eluted with $0.2 M$ acetic acid. Extracted 


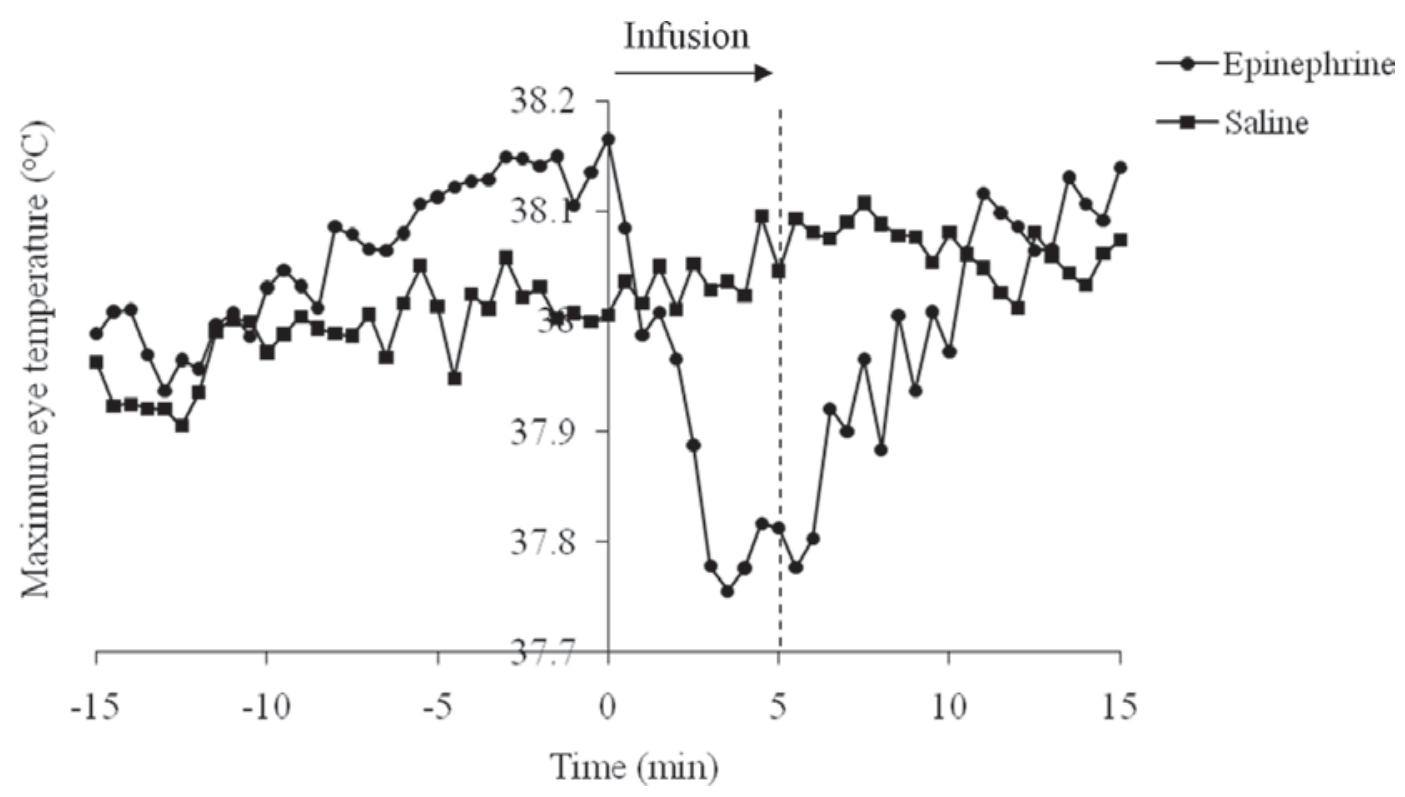

Figure 1. Maximum eye temperature $\left({ }^{\circ} \mathrm{C}\right)$ following infusion $(0$ to $5 \mathrm{~min})$ of epinephrine $(\boldsymbol{\bullet}, \mathrm{n}=8)$ or saline $(\mathbf{\square}, \mathrm{n}=8)$.

epinephrine and norepinephrine were separated and measured by reverse-phase HPLC with electrochemical detection as described previously (Goldstein et al., 1981; Eisenhofer et al., 1986). The extraction efficiency for $N$-methyl dopamine was $99.3 \%$.

One-way ANOVA was used to compare overall treatment differences in maximum eye temperature and $\mathrm{HR}$ during baseline ( -15 min to 0$)$, during infusion (0 to 5 $\mathrm{min}$ ), and during recovery (5 to $15 \mathrm{~min}$ ) and the differences between these values. When a trend $(P \leq 0.10)$ in overall differences between treatments was detected, contrasts were used to compare the change from baseline for each parameter for each treatment. Treatment effects on cortisol, epinephrine, and norepinephrine concentrations were analyzed by ANOVA. For HRV analysis, the 512 IBI that approximated to the infusion period as well as the 512 IBI immediately following infusion were compared with a baseline of the 512 IBI before infusion. A log-transformation was used before analysis of the frequency domain parameters of HRV and for epinephrine and norepinephrine concentrations. Data from 2 calves were excluded because of recording errors. Data are expressed as mean \pm standard error unless stated otherwise.

Infusion of saline did not affect eye temperature, HR, RMSSD, PCV, or concentrations of plasma cortisol, epinephrine, and norepinephrine during any measurement phase, nor were there significant changes in these variables during the baseline period in animals subsequently infused with epinephrine. Epinephrine infusion resulted in a decrease in mean eye temperature of 0.14 $\pm 0.05^{\circ} \mathrm{C}$ compared with baseline $(P=0.01$; Figure 1$)$.
The decrease was consistent with the reported reduction in eye temperature during disbudding without pain relief $\left(-0.3^{\circ} \mathrm{C}\right.$; Stewart et al., 2008b) and as pain sensation returned as local anesthetic was cleared $\left(-0.6^{\circ} \mathrm{C}\right.$; Stewart et al., 2009), a fright $\left(-0.3^{\circ} \mathrm{C}\right)$, and an electric prod $\left(-0.4^{\circ} \mathrm{C}\right.$; Stewart et al., 2008a). The magnitude of the decrease was less extensive than that found in response to a painful experience. This would be expected because a pain response would elicit a cascade of physiological responses not confined to ANS activity alone. The results support the hypothesis that an epinephrine infusion will result in a decrease in eye temperature and provide further support for the view that sympathetically mediated vasoconstriction is the basis of the decreases in eye temperature reported in response to noxious stimuli in cattle (Stewart et al., 2008b).

Plasma norepinephrine concentrations decreased by half $(P<0.01)$ during epinephrine infusion compared with the baseline period, but individual responses were variable and differences between treatments were not significant (Figure 2). Epinephrine infusion increased mean plasma epinephrine concentrations 90 -fold from baseline during the infusion period, and concentrations remained high during the recovery period compared with that observed with saline $(P<0.001)$. The dose was sufficient to increase plasma epinephrine concentrations to higher levels than those reported during an exogenous stressor such as weaning (Lefcourt and Elsasser, 1995), surgical castration (Stewart et al., 2010), branding (Lay et al., 1992a,b), and dehorning (Mellor et al., 2002). Packed cell volumes were similar for both treatments at $-5 \min (33$ vs. $31 \pm 0.1 \%$, epinephrine 
vs. saline, respectively), but higher after epinephrine infusion (38 vs. $31 \pm 0.1 \%$ ), epinephrine vs. saline, respectively; $P<0.001$ ). This increase in $\mathrm{PCV}$ is an indicator of splenic contraction during endogenous epinephrine release (Potocnik and Wintour, 1996), which supports the view that the infusion simulated an SNS response.

Although a high level of individual variability was observed in HR responses to epinephrine infusion, mean HR during the epinephrine infusion period tended to be lower than in the saline-infused calves $(P=0.061$; Figure 3). Compared with baseline, HR decreased by $9.3 \pm$ 3.3 beats $/ \min (P=0.014)$ during epinephrine infusion. During recovery, this was followed by an increase in HR compared with that of the infusion period by $14.7 \pm 2.8$ beats $/ \min (P<0.001)$, and was subsequently higher $(P<0.05)$ in epinephrine-infused calves than for the saline-infused control calves during the 10-min recovery period. The influence of epinephrine on HR is complex and at times appears paradoxical as the SNS and PNS
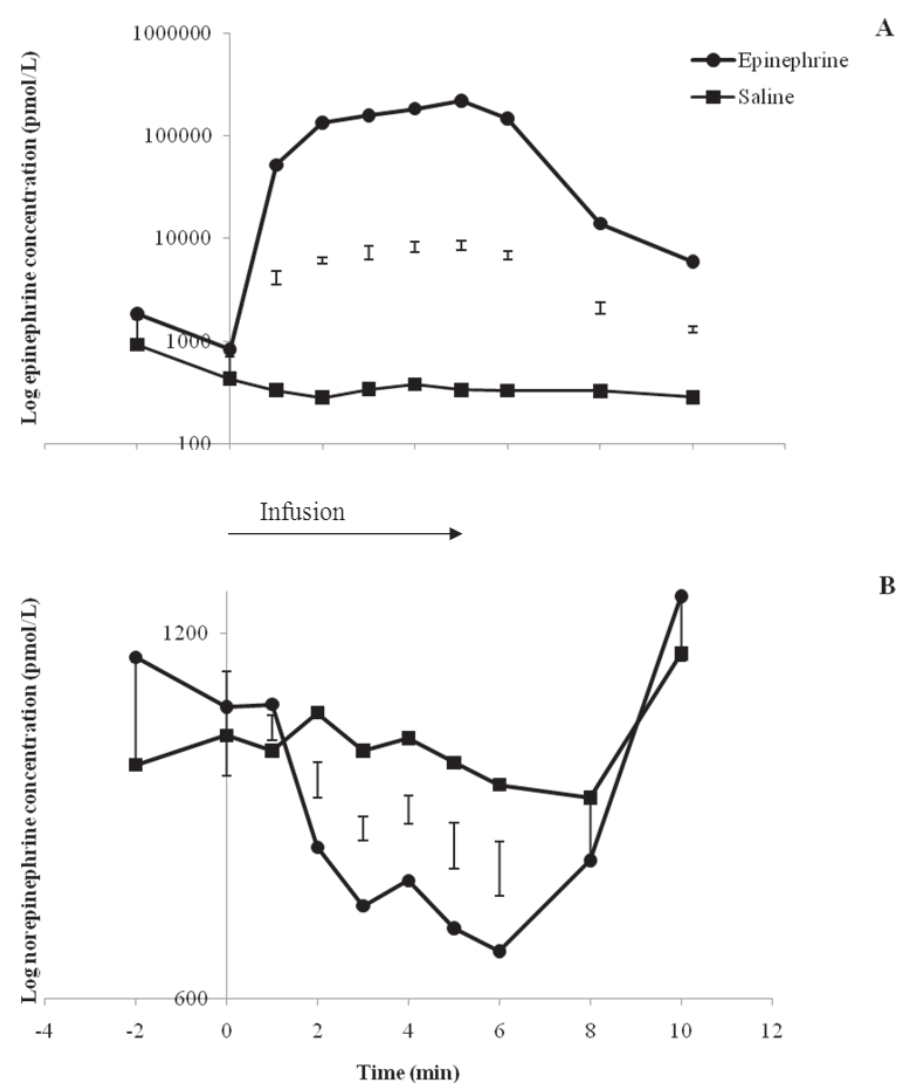

Figure 2. Epinephrine (A) and norepinephrine (B) concentrations following infusion (0 to $5 \mathrm{~min}$ ) of epinephrine $(\boldsymbol{\bullet}, \mathrm{n}=8)$ or saline $(\boldsymbol{\square}$, $\mathrm{n}=8$ ). Means are back transformed. Error bars represent SE of the difference. work in concert to maintain homeostasis. Heart rate increased following epinephrine infusion $(0.05 \mu \mathrm{g} / \mathrm{kg}$ per min) in adult humans (Ahmed et al., 1994) and horses $(1 \mu \mathrm{g} / \mathrm{kg}$ per min; Gehlen et al., 2005), but decreased in anesthetized children $(0.5 \mu \mathrm{g} / \mathrm{kg}$; Wodey et al., 2003). In the present study, the decrease in HR was associated with a significant increase in the RMSSD. During the epinephrine infusion, the RMSSD increased by $49.7 \pm$ $9.2 \mathrm{~ms}(P<0.001)$ compared with baseline and was greater $(P<0.05)$ than for saline-infused calves $(84.5$ \pm 14.6 vs. $30.9 \pm 12.6 \mathrm{~ms}$, epinephrine vs. saline, respectively), indicating a simultaneous increase in PNS activity. During recovery, RMSSD decreased $(P<0.001)$ to baseline levels. The decline in plasma norepinephrine concentrations in the epinephrine-infused calves also indicated that the infusion altered PNS tone.

Plasma cortisol concentrations were similar for both treatments during the baseline period and then increased $(P<0.001)$ by $10.4 \pm 1.7 \mathrm{ng} / \mathrm{mL}$ in epinephrine-infused animals by the end of the recovery period. There was no change in plasma cortisol concentrations from baseline in saline-infused calves $(-0.1 \pm 1.9 \mathrm{ng} / \mathrm{mL})$, suggesting that the handling and infusion procedures did not activate HPA axis response mechanisms. The increase in plasma cortisol concentrations in epinephrine-infused calves must be due to the actions of epinephrine. One possible explanation is that epinephrine infusion produced an increase in splanchnic blood flow, which could result in a greater presentation rate of $\mathrm{ACTH}$ to the adrenal cortex. The adrenal cortex is subject to direct splanchnic nerve inputs, which may influence cortisol release. Experimental evidence for this is that sympathetic denervation of the adrenal gland reduced plasma cortisol response to ACTH treatment compared with that in sham-operated calves (Edwards and Jones, 1993); thus, by inference, an increased SNS tone could lead to release of cortisol.

In conclusion, the observed decrease in eye temperature in response to epinephrine infusion is evidence that this change is sympathetically mediated. This supports the use of eye temperature measurements in studies of acute fear and pain in cattle. The decrease in plasma norepinephrine concentrations and HR, as well as the increase in RMSSD during the epinephrine infusion, suggests that the infusion induced a compensatory increase in PNS activity. The use of IRT has limitations regarding collection of images and complexity of analysis. For example, images must be collected out of direct sunlight and for consistency of the distance and angle that the images are collected from the animal, some restraint or confinement is beneficial. The IRT equipment is portable and simple to use. The use of 


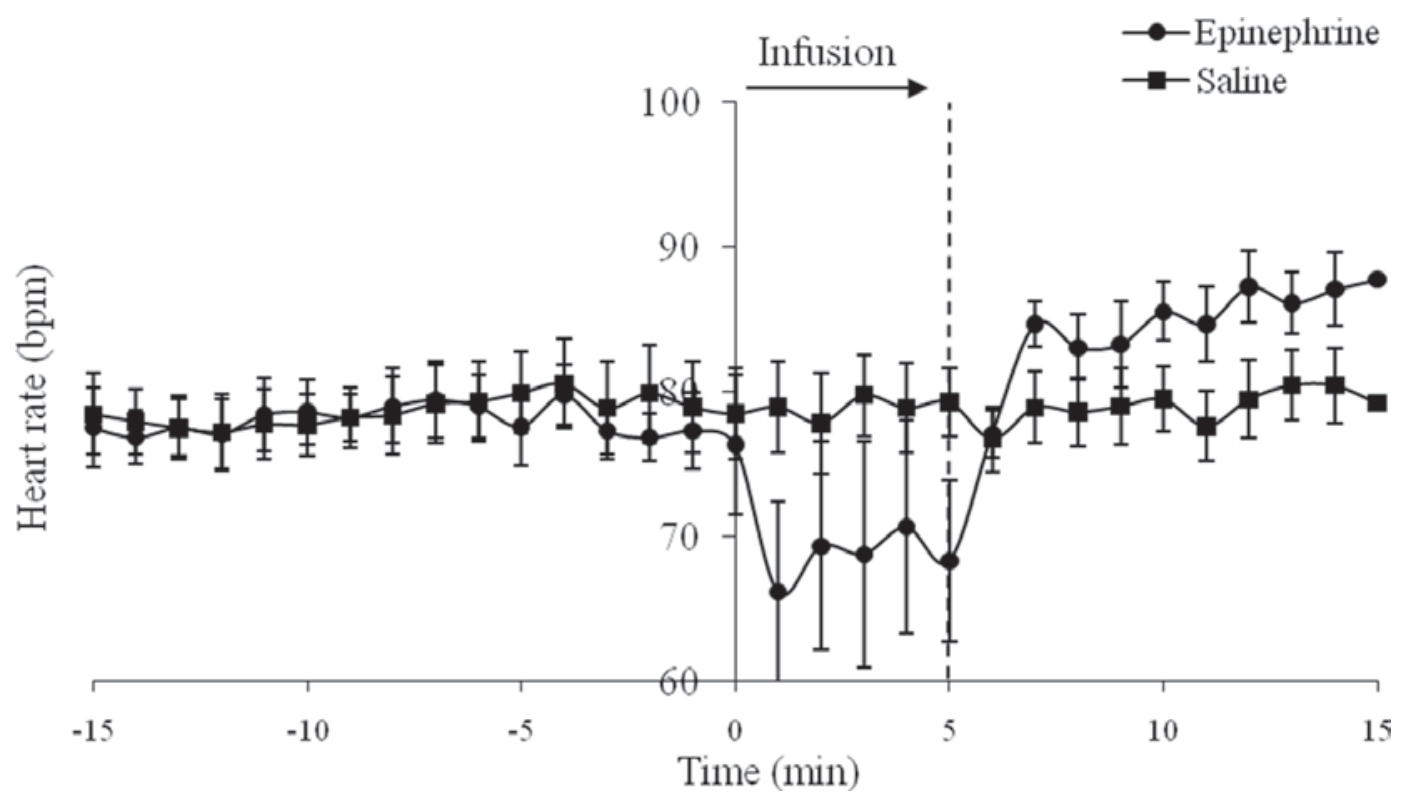

Figure 3. Heart rate (beats/min) \pm SEM following infusion (0 to $5 \mathrm{~min}$ ) of epinephrine $(\boldsymbol{\bullet}, \mathrm{n}=8)$ or saline $(\boldsymbol{\square}, \mathrm{n}=8)$.

IRT is a practical, noninvasive method for measuring ANS activity and assessing welfare of cattle.

\section{ACKNOWLEDGMENTS}

The authors thank AgResearch staff Kate Clark, Gemma Worth, Andrea Rogers and Frankie Huddart, and DairyNZ staff Peter Gore and Kate Watkins for their valuable technical assistance, as well as the AgResearch farm staff. This study was funded by the Foundation for Research, Science and Technology, New Zealand, and DairyNZ Inc.

\section{REFERENCES}

Ahmed, M. W., A. H. Kadish, M. A. Parker, and J. J. Goldberger. 1994. Effect of physiologic and pharmacologic adrenergic stimulation on heart rate variability. J. Am. Coll. Cardiol. 24:1082-1090.

Edwards, A. V., and C. T. Jones. 1993. Autonomic control of adrenal function. J. Anat. 183:291-307.

Eisenhofer, G., D. S. Goldstein, R. Stull, H. R. Keiser, T. Sunderland, D. L. Murphy, and I. J. Kopin. 1986. Simultaneous liquidchromatographic determination of 3,4-dihydroxyphenylglycol, catecholamines, and 3,4-dihydroxyphenylalanine in plasma, and their responses to inhibition of monoamine oxidase. Clin. Chem. 32:2030-2033.

Fisher, A. D., G. A. Verkerk, C. J. Morrow, and L. R. Matthews. 2002. The effects of feed restriction and lying deprivation on pituitary-adrenal axis regulation in lactating cows. Livest. Prod. Sci. 73:255-263.

Gehlen, H., S. Marnette, and P. Stadler. 2005. The influence of adrenaline on echocardiographic parameters of left ventricular function in the horse. Equine Comp. Exerc. Physiol. 2:89-96.

Goldstein, D. S., G. Feuerstein, J. L. Izzo, I. J. Kopin, and H. R. Keiser. 1981. II. Validity and reliability of liquid chromatography with electrochemical detection for measuring plasma levels of norepinephrine and epinephrine in man. Life Sci. 28:467-475.
Hjemdahl, P. 1993. Plasma catecholamines-analytical challenges and physiological limitations. Baillieres Clin. Endocrinol. Metab. 7:307-353.

Kolver, E. S., J. R. Roche, M. J. De Veth, and T. R. Mackle. 2001 Lipolytic response of New Zealand and overseas Holstein-Friesian dairy cows challenged with epinephrine. Pages $48-51$ in Proc NZ Soc. Anim. Prod., Lincoln University, Christchurch, New Zealand.

Lay, D. C., T. H. Friend, K. K. Grissom, C. L. Bowers, and M. E. Mal. 1992a. Effects of freeze or hot-iron branding of Angus calves on some physiological and behavioural indicators of stress. Appl. Anim. Behav. Sci. 33:137-147.

Lay, D. C., T. H. Friend, R. D. Randel, C. L. Bowers, K. K. Grissom and O. C. Jenkins. 1992b. Behavioral and physiological effects of freeze or hot-iron branding on crossbred cattle. J. Anim. Sci. 70:330-336.

Lefcourt, A. M., and T. H. Elsasser. 1995. Adrenal responses of Angus $\times$ Hereford cattle to the stress of weaning. J. Anim. Sci. 73:2669-2676

Locatelli, A., P. Sartorelli, F. Agnes, G. P. Bondiolotti, and G. B. Picotti. 1989. Adrenal response in the calf to repeated simulated transport. Br. Vet. J. 145:517-522.

Mellor, D. J., K. J. Stafford, S. E. Todd, T. E. Lowe, N. G. Gregory, R. A. Bruce, and R. N. Ward. 2002. A comparison of catecholamine and cortisol responses of young lambs and calves to painful husbandry procedures. Aust. Vet. J. 80:228-233.

Niskanen, J. P., M. P. Tarvainen, P. O. Ranta-Aho, and P. A. Karjalainen. 2004. Software for advanced HRV analysis. Comput. Methods Programs Biomed. 76:73-81.

Potocnik, S. J., and E. M. Wintour. 1996. Development of the spleen as a red blood cell reservoir in lambs. Reprod. Fertil. Dev. 8:311315.

Stewart, M., A. L. Schaefer, D. B. Haley, N. J. Cook, K. J. Stafford, and J. R. Webster. 2008a. Infrared thermography as a non-invasive method for detecting fear-related responses of cattle to handling procedures. Anim. Welf. 17:387-393.

Stewart, M., K. J. Stafford, S. K. Dowling, A. L. Schaefer, and J. R. Webster. 2008b. Eye temperature and heart rate variability of calves disbudded with or without local anaesthetic. Physiol. Behav. 93:789-797.

Stewart, M., J. M. Stookey, K. J. Stafford, C. B. Tucker, A. R. Rogers, S. K. Dowling, G. A. Verkerk, A. L. Schaefer, and J. R. Webster. 
2009. Effects of local anesthetic and a non-steroidal anti-inflammatory drug on pain responses of dairy calves to hot-iron dehorning. J. Dairy Sci. 92:1512-1519.

Stewart, M., G. A. Verkerk, K. J. Stafford, A. L. Schaefer, and J. R. Webster. 2010. Non-invasive assessment of autonomic activity for evaluation of pain in calves, using surgical castration as a model. J. Dairy Sci. 93:3602-3609.

Stewart, M., J. R. Webster, A. L. Schaefer, N. J. Cook, and S. L. Scott. 2005. Infrared thermography as a non-invasive tool to study animal welfare. Anim. Welf. 14:319-325.

Stewart, M., J. R. Webster, G. A. Verkerk, A. L. Schaefer, J. J. Colyn, and K. J. Stafford. 2007. Non-invasive measurement of stress in dairy cows using infrared thermography. Physiol. Behav. 92:520525.

Task Force of the European Society of Cardiology and the North American Society of Pacing and Electrophysiology. 1996. Heart rate variability: Standards of measurement, physiological interpretation and clinical use. Circulation 93:1043-1065.

von Borell, E., J. Langbein, G. Despres, S. Hansen, C. Leterrier, J. Marchant-Forde, R. Marchant-Forde, M. Minero, E. Mohr, A. Prunier, D. Valance, and I. Veissier. 2007. Heart rate variability as a measure of autonomic regulation of cardiac activity for assessing stress and welfare in farm animals - A review. Physiol. Behav. 92:293-316.

Wodey, E., L. Senhadji, J. Y. Bansard, A. Terrier, F. Carre, and C. Ecoffey. 2003. Comparison of heart rate response to an epinephrine test dose and painful stimulus in children during sevoflurane anesthesia: Heart rate variability and beat-to-beat analysis. Reg. Anesth. Pain Med. 28:439-444.

Yang, W., and P. P. T. Yang. 1992. Literature survey on biomedical applications of thermography. Biomed. Mater. Eng. 2:7-18 